\title{
Diffuse Involvement of Small Bowel in Burkitt's Lymphoma with Intussusception
}

A 5-year-old male presented with pain abdomen, intermittent bilious vomiting, and passage of blood-mixed mucoid stool for 3 days. On examination, he was pale, dehydrated, and tachycardic; there was mild upper abdominal distension with a palpable mass measuring $8 \mathrm{~cm} \times 4 \mathrm{~cm}$ in the left upper abdomen. Per-rectal examination showed an empty rectum with blood-mixed mucus at the tip of the examining finger. His hemoglobin was $9.0 \mathrm{~g} / \mathrm{dl}$; total leukocyte count was $11,400 / \mathrm{mm}^{3}$; serum lactate dehydrogenase (LDH) level was $865 \mathrm{U} / \mathrm{L}$; serum electrolytes and creatinine were within normal limits. Peripheral smear and bone marrow aspiration were not done as the patient presented with acute abdomen and needed urgent surgical intervention. X-ray abdomen revealed a few air-fluid levels in the upper abdomen with distal paucity of gas. Abdominal sonogram showed features of intussusception [Figure 1] with significantly enlarged mesenteric lymph nodes, the largest one measuring $5 \mathrm{~cm} \times 3 \mathrm{~cm}$ in size.

During surgery, several multicentric intramural masses involving the bowel circumference variably were seen to involve both jejunum and ileum [Figure 2a]. The proximal-most lesion among them was the lead point to jejunojejunal intussusception [Figure 2b] which could be reduced manually. Resection was not done due to diffuse involvement of the entire small bowel. One of the enlarged mesenteric lymph nodal masses was excised and sent for histopathological examination (HPE). HPE revealed features of high-grade B-cell non-Hodgkin's lymphoma which was positive for CD20, CD10, and BCL6 and showed high Ki-67 positivity; fluorescence in situ hybridization study showed a c-MYC translocation suggesting Burkitt's lymphoma [Figure 3].

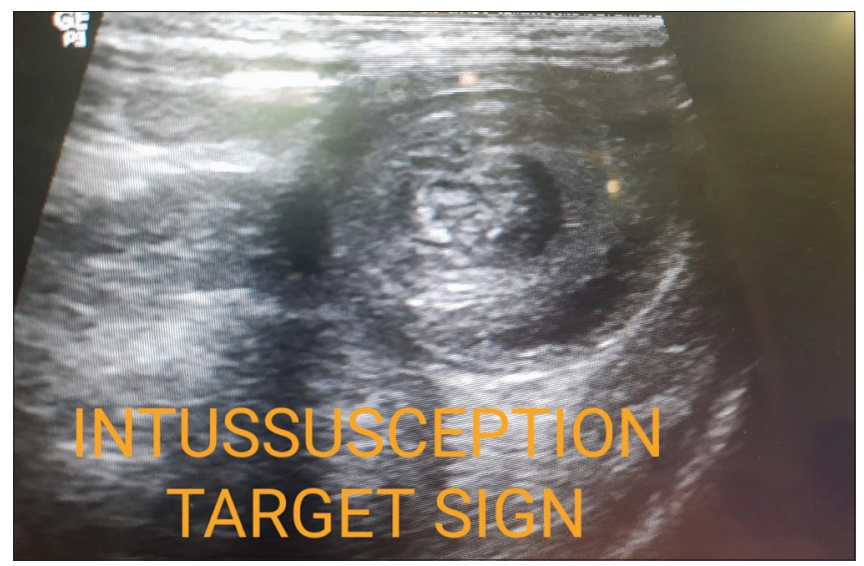

Figure 1: Ultrasound imaging showing loop within loop picture (target sign) suggestive of intussusception
The patient was started on oral feeds from the $5^{\text {th }}$ postoperative day and received chemotherapy following histological diagnosis. Considering the different protocols for chemotherapy in Burkitt's lymphoma for children, he received 4 cycles of modified Magrath regimen (2 cycles of CODOX-M and IVAC alternating every 21 days) without rituximab (due to high cost) after consultation with the medical oncology team; CODOX-M consists of (cyclophosphamide $800 \mathrm{mg} / \mathrm{m}^{2}$ intravenous [IV] on day 1 and day 2; vincristine $1.4 \mathrm{mg} / \mathrm{m}^{2}$ IV on days 1 and 8; cytarabine $50 \mathrm{mg}$ intrathecally [IT] on days 1 and 3; methotrexate $3000 \mathrm{mg} / \mathrm{m}^{2} \mathrm{IV}$ over $4 \mathrm{~h}$ on day 10 and then again $12 \mathrm{mg}$ IT on day 15; leucovorin $200 \mathrm{mg} / \mathrm{m}^{2} \mathrm{IV}$ $24 \mathrm{~h}$ after initiation of methotrexate on day 11, followed by $15 \mathrm{mg} / \mathrm{m}^{2}$ IV every $6 \mathrm{~h}$ and granulocyte colony stimulating factor [G CSF] from day 13 till absolute granulocyte count $\geq 1 \times 109 / \mathrm{L}$ ); IVAC consists of (cytarabine $2 \mathrm{mg} /$ $\mathrm{m}^{2}$ IV every $12 \mathrm{~h}$ for 4 doses from day 1 ; etoposide 60 $\mathrm{mg} / \mathrm{m}^{2} \mathrm{IV}$ on days $1-5$; ifosfamide $1500 \mathrm{mg} / \mathrm{m}^{2} \mathrm{IV}+$ mesna $360 \mathrm{mg} / \mathrm{m}^{2}$ on days $1-5$; methotrexate $12 \mathrm{mg}$ IT on day 5; leucovorin $15 \mathrm{mg}$ orally $24 \mathrm{~h}$ after IT methotrexate on day 6; G CSF $5 \mu \mathrm{g} / \mathrm{kg}$ subcutaneous daily from day 7 till absolute granulocyte count $\geq 1 \times 109 / \mathrm{L}$ ). ${ }^{[1]}$ During this period, complete blood count, serum electrolytes, uric acid levels, LDH, creatinine and creatinine clearance, evidence of mucositis, neurotoxicity, hepatotoxicity (serum bilirubin level), cardiotoxicity (echocardiography), and serum methotrexate levels were monitored. This is a highly efficacious regimen, and the patient responded to it. Compared to continuous infusion approaches, this regimen was easy to administer and cost and issues related to infusion pumps and central venous catheters were not there. ${ }^{[1]}$

The patient is symptom free in the postoperative period and has been in regular follow-up since the last 12 months.

Lymphomas are common lead points in intussusceptions seen in older children. Multicentric diffuse involvement of bowel in lymphoma, as seen in this case, has also been

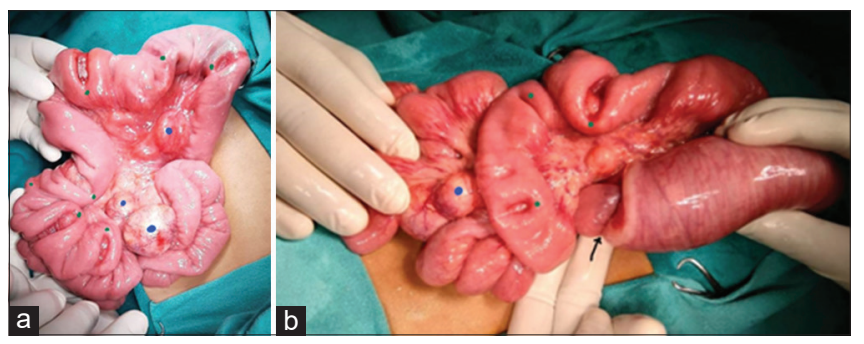

Figure 2: $(a$ and $b)$ Intraoperative pictures of the patient showing multiple circumferential lesions, enlarged lymph nodes, and intussusception 


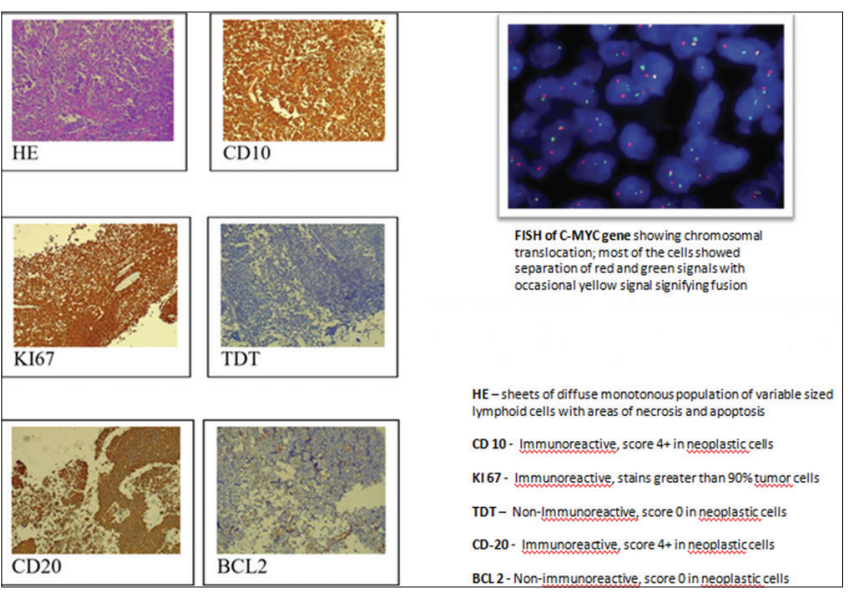

Figure 3: Histopathological examination slides suggesting a B-cell non-Hodgkin's lymphoma (HE, CD10, KI67, TDT, CD20, and BCL2) and picture of fluorescence in situ hybridization showing C-MYC translocation

reported earlier. ${ }^{[2,3]}$ While single or segmental involvement makes resection and anastomosis possible, diffuse involvement of the entire small bowel as seen in this case forbids resection, and therefore, chemotherapy is the only effective modality of treatment after manual reduction of intussusception.

\section{Declaration of patient consent}

The authors certify that they have obtained all appropriate patient consent forms. In the form, the parents have given their consent for images and other clinical information to be reported in the journal. The parents understand that name and initials will not be published, and due efforts will be made to conceal identity, but anonymity cannot be guaranteed.

Financial support and sponsorship

Nil.

\section{Conflicts of interest}

There are no conflicts of interest.
Digamber Chaubey, Sandip Kumar Rahul, Sujit Kumar, Ramdhani Yadav

Department of Paediatric Surgery, Indira Gandhi Institute of Medical Sciences, Patna, Bihar, India

Address for correspondence: Dr. Sandip Kumar Rahul, S/O Shri Kapil Kumar Jha, Qr. No. - BN-2/B, IGIMS Campus, Patna - 800 014, Bihar, India. E-mail: sandeep.rahul65@gmail.com

Submitted: 06-May-2020

Revised: 01-Aug-2020

Accepted: 23-Aug-2020

Published: 31-Dec-2020

\section{References}

1. Lacasce A, Howard O, Lib S, Fisher D, Weng A, Neuberg D, et al. Modified magrath regimens for adults with Burkitt and Burkitt-like lymphomas: preserved efficacy with decreased toxicity. Leuk Lymphoma 2004;45:761-7.

2. Gupta H, Davidoff AM, Pui CH, Shochat SJ, Sandlund JT. Clinical implications and surgical management of intussusception in pediatric patients with Burkitt lymphoma. J Pediatr Surg 2007;42:998-1001.

3. Özant A, Arslan K, Özçay N, Besim H. Adult multicentric burkitt lymphoma with bowel obstruction due to intussusception. Turk J Gastroenterol 2018;29:361-4.

This is an open access journal, and articles are distributed under the terms of the Creative Commons Attribution-NonCommercial-ShareAlike 4.0 License, which allows others to remix, tweak, and build upon the work non-commercially, as long as appropriate credit is given and the new creations are licensed under the identical terms.

\begin{tabular}{|l|l|}
\hline \multicolumn{2}{|c|}{ Access this article online } \\
\hline Quick Response Code: & Website: \\
& www.ijmpo.org \\
\cline { 2 - 2 } & DOI: \\
\hline
\end{tabular}

How to cite this article: Chaubey D, Rahul SK, Kumar S, Yadav R. Diffuse involvement of small bowel in Burkitt's lymphoma with intussusception. Indian J Med Paediatr Oncol 2020;41:899-900. 